\title{
Contemporary Problems in Teacher's Work from the International Perspective
}

[Miko-Giedyk J., Joy C., Kashahu Xhelilaj L., Zenelaga B., Sotirofski K. (2020). Contemporary Problems in Teacher's Work - In Poland, the United Kingdom and Albania. Kraków: Oficyna Wydawnicza "Impuls", 152 pp.]

Teacher's work in the modern society is vague. On the one hand it is so because the tools and working conditions seem to be changeable and not trustworthy enough. On the other hand, social expectations are different than the ones made by scientists. Mostly because of the popular myths concerning the teaching profession which present teachers as uncreative, poorly educated and constantly tired and exasperated. That view might be misleading. The authors had an opportunity to get an insight into the everyday life of contemporary teachers and the complexity of their career paths, which was presented in the reviewed book Contemporary problems in teacher's work - in Poland, the United Kingdom and Albania. In this promising book recently published by the Impuls Press, contemporary problems of the teaching profession were widely described in the international context. The book is based on the research conducted in Poland, the United Kingdom and Albania. It presents an innovative analysis of how teachers function nowadays.

The aim of the authors' work, which is comprehensively presented in the extensive introduction, is to ask a question about neoteric teaching profession and its problems. In the introduction the authors present general ideas of the book that can be covers the areas of the sociology of education, comparative pedagogy and contemporary pedeutology. The beginning sections of the book describe previous

* PhD Jakub Adamczewski, Adam Mickiewicz University Poznań, Faculty of Educational Studies, Poland; e-mail: jakub.adamczewski@amu.edu.pl. 
research including significant data on the above-mentioned specializations, which should be treated as a base for further discussion. With this in mind, the authors explain problems and hopes of the current situation of teachers in the participating countries. There are three elaborate chapters and a thought-provoking introduction in this book, all of them follow the same structure: the characteristics of the educational system, the characteristics of the teacher education system, the issues of teacher's professional development and finally, a detailed pedeutological problem or problems in a each of the countries chosen by the author of a particular chapter. It is appropriate to add that the inviting language of the introduction is very personal with lots of important data gathered over the last few years.

Chapter One entitled 'Contemporary Problems in Teacher's Work in Poland' written by Justyna Miko-Giedyk, from the Jan Kochanowski University in Kielce, contains basic knowledge about the Polish education system as well as an extensive analysis of the contemporary teachers' education. Apart from that, the author describes the issues of professional development and promotion in terms of the present situation of teachers in Poland. Miko-Giedyk draws our attention also to the problem of social expectations towards rural teachers. Throughout this part the writer refers to her empirical research which helps the reader understand the problem. I must admit that the author certainly mastered the skill of observation, as the conclusions might make us reflect upon the teaching profession in Poland. The first chapter undoubtedly gives useful and justified data, which helps understand the situation of Polish teachers.

The second section called 'Contemporary problems in teacher's work in the United Kingdom' is focused on the systematic analysis of the modern educational situation in the United Kingdom. This is a reflection presented by Joy Carroll, a researcher from the University of Worcester. In this chapter, a reader will find the detailed characteristics of the education system in all countries belonging to the UK. It was incredibly interesting to me to see how different the concept of teachers' education is in each country within the UK, although there are many similarities. The professional development of teachers as well as the distribution of school responsibilities between teachers and support staff were raised also in part three and four. The author focused on historical contexts of the policy of education in England, fundamental values and the evolving role of a teaching assistant in British schools. This part of the book represents valuable and innovative approach, especially for those interested in comparative education.

The final chapter of this publication 'Contemporary problems in teacher's work in Albania' addresses the question of the current teachers' situation from the researchers' perspective. This part was written by the team of observant lecturers from the University in Durres and Tirana. The main idea presented in this part is to describe and discuss the current structure of the education system and possible paths of education for teachers. Additionally, the authors mention the opportunities for professional development of teachers. Again, what was particularly appealing 
to me was the final part, which was dedicated to the crucial problems faced by teachers in Albania. Those problems especially concern the quality of teachers, working conditions, interpersonal relationships among school staff as well as a bond of friendship (or its lack?) between teachers and students together with parents. On the whole, this chapter gives a deep insight into challenges that are to be faced by Albanian society.

The book has led me to the conclusion that the pedeutological issues should be more visible in the academic discourse. I should mark that this might be one of the best recent publications presenting the reality of contemporary teachers in Poland, Albania and the UK. The authors managed to pique my interest thanks to the relevant data and a critical approach to the past and future of the teachers. All in all, the findings discussed in this review highlight the important role of this publication in providing the better understanding of similarities and differences in becoming and working as a teacher in the quickly evolving environment. 



\title{
KRONIKA
}

\author{
Forum Pedagogiczne \\ $10(2020) 2$ \\ Wpłynęło: 13.01.2020 \\ Zatwierdzono do druku: 24.06 .2020 \\ DOI: $10.21697 / \mathrm{fp} .2020 .2 .24$
}

DARIUSZ STĘPKOWSKI*

Warszawa, Polska

ORCID ID: https://orcid.org/oooo-0oo2-6855-1517

\section{Sprawozdanie z międzynarodowej konferencji naukowej pt. „Ethics and Education”, Warszawa, 29-30 listopada 2019 roku}

„Ethics and Education” to tytuł cyklu konferencji odbywającego się co dwa lata na Wydziale Pedagogicznym Uniwersytetu Warszawskiego. W roku 2019 była to już piąta edycja tego wydarzenia naukowego. W dwudniowych obradach wzięło udział w sumie 16 naukowców z ośmiu krajów: ośmiu z Polski, dwóch z Hiszpanii i po jednym z Belgii, Holandii, Izraela, Stanów Zjednoczonych, Wielkiej Brytanii i Włoch. Organizatorem konferencji był Rafał Godoń, który jednocześnie pełnił obowiązki gospodarza i moderatora podczas wszystkich sesji.

Obrady zostały podzielone na 10 sesji. Każda sesja składała się z dwóch wystąpień i dyskusji po każdym referacie. Między sesjami odbywały się 15-minutowe przerwy.

Otwarcia konferencji dokonał Rafał Godoń, który w skrócie przypomniał wiodącą ideę warszawskich spotkań - promocję filozofii edukacji w Polsce. Rolę ojców założycieli tejże serii konferencji odgrywają Joanna Górnicka-Kalinowska i z Uniwersytetu Warszawskiego i Stefaan Cuypers z Catholic University w Luwanium, którzy w 2011 roku zorganizowali pierwsze spotkanie.

Po naszkicowaniu programu obrad R. Godoń otworzył pierwszą sesję i poprosił o zabranie głosu keynote speaker - Giuseppinę D’Addelfio z University of Palermo we Włoszech. Tytuł jej referatu brzmiał: The importance of values in education. A phenomenological challenge to the contemporary moral subjectivism. Prelegentka skupiła się na charakterystyce postaci Dietricha von Hildebranda i przedstawieniu jego stanowiska filozoficznego. Jej zdaniem zasługuje on na szczególną uwagę nie tylko $z$ tego powodu, że rozwinął koncepcję stojącą w opozycji wobec Maxa

\footnotetext{
* Dr hab. Dariusz Stępkowski, prof. ucz., Uniwersytet Kardynała Stefana Wyszyńskiego w Warszawie, Wydział Nauk Pedagogicznych; e-mail: d.stepkowski@uksw.edu.pl.
} 
Schelera, lecz również dlatego że wynikają z niej interesujące implikacje dla współczesnego wychowania i kształcenia moralnego.

W rozwoju myślenia fenomenologicznego D. von Hildebranda prelegentka zwróciła uwagę na przyczynę rozejścia się jego drogi filozofowania i z drogą M. Schelera. Jej zdaniem, kluczowe znaczenie miała odmienna interpretacja słynnej metafory jaskini Platona. Przygotowując rozprawę doktorską, D. von Hildebrand uznał, że niewystarczające jest przyjęcie przedmiotów ukazujących się kajdaniarzom na ścianie jako źródłowych, lecz założył, że wraz z pojawianiem się na ścianie jaskini dane jest coś jeszcze, a mianowicie rozdzielenie (gr. chorismos). Jednym z przejawów tego zjawiska jest rozróżnienie mowy i myślenia - nie są one tożsame. Ta właściwość stała się dla D. von Hildebranda podstawą do stworzenia koncepcji wartości, która całkowicie odbiega od Schelerowskiej. W ujęciu pierwszego badacza wartość nie wiąże się głównie z oceną emocjonalną, lecz jest tym, co jawi się podmiotowi bezpośrednio $\mathrm{w}$ związku $\mathrm{z}$ rozpoznaniem przedmiotu i co oddziałuje na podmiot jako bezwzględne wezwanie. Głos wartości niejako zmusza podmiot do określonego zachowania, ale poprzedza go wysiłek skierowany na rozpoznanie wartości. Konsekwencją zaś tego jest transcendowanie siebie samego przez działanie zgodne z wartością.

Odnosząc zrekonstruowaną koncepcję D. von Hildebranda do edukacji moralnej, G. D’Addelfio wyraziła nadzieję, że edukacja ta przestanie być odczytywana jako budowanie subiektywności rozumianej jako egocentryczne skupienie podmiotu na sobie samym i swoich odczuciach, i zacznie być rozumiana jako otwarcie na to, co umożliwia człowiekowi transcendowanie siebie.

Po dyskusji gospodarz zaprosił na przerwę kawową, a po niej odbyła się druga sesja. Złożyły się na nią dwa wystąpienia. Jako pierwszy zabrał głos Daniel Bruk $\mathrm{z}$ The Hebrew University w Jerozolimie (Izrael), który przedstawił referat pt. Monolingual doctrine in early Jewish settlement in Palestine and it's influence on Israel's language education today. Prelegent nakreślił najpierw sięgające przełomu XIX i XX wieku początki kształtowania się języka hebrajskiego jako nowoczesnego, który po II wojnie światowej został wprowadzony w Izraelu jako język państwowy. Następnie przedstawił proces rozpowszechniania się tego języka w nowym państwie żydowskim i trudności, na jakie do dziś dnia ten proces natrafia. Za kluczowe podejście w określeniu roli języka hebrajskiego D. Bruk uznał rewolucję wielokulturową, jaka dokonała się w latach 6o. XX wieku. To dzięki niej możliwy obecnie istniejący tzw. statyczny pluralizm. Polega on na tym, że w państwie Izrael dopuszcza się posługiwanie się różnymi językami, które jednakże nie mogą zastępować języka hebrajskiego.

Drugi referat przedstawiony w tej sesji wygłosili Stanisław Gałkowski i Paweł Kaźmierczak z Akademii Ignatianum w Krakowie. Jego tytuł brzmiał: Docility vs. jadedness. The basis of commitment in education. Osią ich rozważań było zestawienie dwóch fenomenów: „pouczalności”, rozumianej jako gotowość do przyjmowania pouczeń, i zjawiska Blasiertheit (pol. „zblazowanie”), które nazwał i opisał 
niemiecki socjolog kultury Georg Simmel w 1903 roku, w opublikowanym wówczas tekście pt. Mentalność mieszkańców wielkich miast. Upraszczając, można powiedzieć, że polega ono na braku zaangażowania i obojętności, co dość powszechnie można zauważyć wśród uczniów i studentów. Według Rorty’ego, taka postawa prowadzi do relatywizmu moralnego, ponieważ podważa ona wiarę w autorytet i gotowość do powierzenia się mu. Prelegenci nie dali w swoim wystąpieniu odpowiedzi na pytanie, jak zachęcić młodych ludzi do zaangażowania się we własne kształcenie. Ich zdaniem „zblazowanie” jest jedną z ważniejszych przyczyn obecnego kryzysu nauczania i uczenia się.

Jak zwykle po referacie odbyła się dyskusja. Po niej zaproszono uczestników na lunch, a następnie odbyła się trzecia sesja tematyczne. Zaprezentowano w niej znowu dwa referaty. Pierwszy przedstawił Alberto Sánchez-Rojo z The Complutense University w Madrycie (Hiszpania). Tytuł wystąpienia brzmiał: The ethical value of learning to wait. Going back to Herbarts's educational theory. Prelegent rozpoczą od uwagi, że słowo „oczekiwać” wzbudza najczęściej negatywne skojarzenia. Oznacza bowiem niemożność osiągnięcia czegoś. W tym kontekście dokonał rozróżnienia dwu wyrazów w języku angielskim, stosowanych do wyrażania oczekiwania expect i wait. Pierwszy wyraz dotyczy oczekiwania czegoś konkretnego, drugi nie ma konotacji teleologicznej i oznacza raczej nastawienie.

Po tych rozróżnieniach terminologicznych A. Sánchez-Rojo omówił, jaką funkcję pełni termin „oczekiwanie” (wait) w koncepcji pedagogicznej Herbarta. Jego zdaniem koncepcja ta napotyka na duże trudności również $\mathrm{z}$ powodu innego współcześnie podejścia do zjawiska czasu. Czekanie odmierzane czasem nie jest tym czekaniem, o które chodzi w kształceniu. Jest ono postawą, dzięki której uczący się oczekuje dalszego kroku w procesie kształcenia, ale nie zasadzie osiągnięcie czegoś, co sprawia, że zaprzestaje działania, lecz właśnie inicjowania następnych kroków. Kształcenie szkolne, utożsamiane z transmisją wiedzy, unicestwia właściwie oczekiwanie w Herbartowskim sensie tego słowa.

Drugim prelegentem w tej sesji był Marcin Rebes z Uniwersytetu Jagiellońskiego $\mathrm{w}$ Krakowie. Swój referat zatytułował on: The role of the principle and experience of solidarity in modern society. An educational perspective.

Po kolejnej przerwie rozpoczęła się czwarta sesja. W niej jako pierwszy głos zabrała Arleta Suwalska z Uniwersytetu Łódzkiego, która przedstawiła temat: The subject of ethics in National Core Curriculum for general upper secondary schools 2015 in Finland. Na podstawie przeprowadzonych analiz, które przedstawiła w swojej rozprawy doktorskiej, przekonywała, że źródłem sukcesu fińskiego systemu edukacyjnego jest wcielenie w życie idei edukacyjnych rozwijanych w minionym stuleciu, a zasygnalizowanych w międzynarodowych dokumentach poświęconych problemowi kształcenia, takich jak: nauczanie zindywidualizowane, kooperacja, zaufanie, myślenie krytyczne, rozwiązywanie problemów itp.

Zgodnie ze zwyczajem po tym wystąpieniu oddano głos drugiemu prelegentowi. Był nim Jan Rutkowski z Uniwersytetu Warszawskiego. Tytuł jego wystąpienia 
brzmiał: Usefulness of modern science and education. Wychodząc od konstatacji, że nauka stanowi istotę kultury zachodnio-europejskiej i północno-amerykańskiej, prelegent rozważył związek zachodzący między filozofią i nauką w starożytności a w czasach współczesnych. Na tej podstawie poddał krytyce dominującą dziś tendencję do poszukiwania w wiedzy przede wszystkim użyteczności. Jego zdaniem, szkodzi ona nie tylko filozofii, lecz także naukom pozytywnym, których rola redukowana jest do dostarczania narzędzi do nowoczesnego postępu technologicznego.

Po ostatniej tego dnia przerwie na kawę rozpoczęła się piąta sesja, a w niej kolejne dwa referaty. Pierwszy wygłosił Nicholas Burbules z University of Illinois w Urbana-Champaigne (USA). Swój referat autor zatytułował The practice of virtue. Za Alasdairem MacIntyrem zaapelował on o ponowne odkrycie cnót. Żeby teoria cnoty mogła przerodzić się w praktykę, zaprezentował pięć zasad, Wszystkie one zostały skonstruowane według zbieżnego rozumowania, a mianowicie zachęty do zmiany w perspektywie patrzenia: (1) z uniwersalistycznej na prospołeczną; (2) z indywidualistycznej na wspólnotową; (3) z teoretycznej na praktyczną; (4) z instrumentalnej na pragmatyczną i (5) z ekskluzyjnej na inkluzyjną. Rozważania teoretyczne zilustrował przykładem nowoczesnego odczytania, czym jest cnota uczciwości (ang. honesty). Interesująca była uwaga N. Burbulesa odnośnie istoty filozofii wychowania. Jego zdaniem nie należy jej rozumieć jako aplikacji teorii filozoficznych do problemów pedagogicznych, lecz odczytanie pedagogicznego wymiaru kwestii filozoficznych.

Pierwszy dzień zakończyło spotkanie doktorantów uczestniczących konferencji.

Obrady wznowiono następnego dnia o godz. 10. Tak samo jak w poprzednim dniu odbyło się pięć sesji tematycznych, złożonych każdorazowo z dwóch referatów, dyskusji i przerwy. W szóstej sesji jako pierwszą poproszono o zabranie głosu Tanię Alonso-Sainz z The Autonomous University w Madrycie (Hiszpania). Tytuł jej wystąpienia brzmiał: Teachers as strong evaluators: an approach from Charles Taylor. Biorąc za punkt wyjścia niedawno sformułowany zarzut przeciwko teoretykom, w szczególności filozofom edukacji, zgodnie z którym nie mają oni doświadczenia praktycznego w pracy z dziećmi i młodzieżą, prelegentka rozważyła kwestię zależności między praktyką i teorią pedagogiczną. W drugiej części swojego wystąpienia, odwołując się do Charlesa Taylora, scharakteryzowała nastawienie naturalistyczne wobec danych empirycznych, i przeciwstawiła je postawie ewaluatora, któremu przypisała atrybut „silny” (ang. strong). W ten sposób T. Alonso-Sainz wskazała na potrzebę kształtowania u nauczycieli umiejętności rozumienia i wartościowania danych empirycznych uzyskiwanych $\mathrm{z}$ różnorodnych pomiarów efektywności ich pracy. Od tego zależy jej zdaniem trafność wyciąganych wniosków praktycznych.

Drugi referat w ten sesji - Good and evil as explanatory concepts in educational program - przedstawiła Joanna Górnicka-Kalinowska z Uniwersytetu Warszawskiego. Prelegentka osnową swoich rozważań uczyniła kwestię tego, czy i w jakim zakresie koncepcje zła mogą być przedmiotem wychowania i kształcenia moralnego. W związku z tym scharakteryzowała różnorakie teorie filozoficzne 
i niefilozoficzne zła i jego rozumienia, wskazując na ich złożoność i problematyczność w kontekście edukacyjnym. Pytanie, czy i jak można je zastosować w edukacji, pozostało właściwie bez satysfakcjonującej odpowiedzi.

Po przerwie na kawę odbyła się siódma sesja, w której przedstawiony został tylko jeden referat. Prelegentem był niżej podpisany. Tytuł wystąpienia brzmiał: A concept of a self-logical normativity of education and their relation to other normativity claims. Autorem referatu był Dietrich Benner, który z ważnych powodów osobistych nie mógł przybyć do Warszawy. Przedmiotem referatu było rozróżnienie między działaniem pedagogicznym i właściwą mu normatywnością a innymi rodzajami ludzkiego działania, którym również przysługuje odpowiednia normatywność. Jako przykład ilustrujący to rozróżnienie został omówiony film dokumentalny pt. Elternschule (pol. Szkoła dla rodziców). W filmie tym przedstawiono interwencje terapeutyczne nakierowane na dzieci, które wskutek błędów wychowawczych rodziców nie osiągnęły samosterowności i nie są zdolne wydobyć się z tego stanu o własnych siłach.

Następną sesję poprzedziła kolejna przerwa na kawę. Zgromadzeni wysłuchali $\mathrm{w}$ niej referatu wygłoszonego przez Stefaana Cuypersa $\mathrm{z}$ Catholic University of Leuven (Belgia), zatytułowanego R.S. Peters' philosophy of moral education in relation to his Freudian psychology. Z wnikliwością i znawstwem autor zapoznał zebranych z niuansami teorii edukacji liberalnej R.S. Petersa, którego postać zainteresowała badacza nie tylko ze względów zawodowych, lecz także osobowych.

Po tym gospodarz konferencji zaprosił zebranych na obiad. Następnie przystąpiono do kolejnej sesji. Najpierw głos zabrała Ursula Blythe z Kings College w Londynie (Wielka Brytania). Tytuł jej referatu brzmiał Cross-cultural education: a philosophical critique of Mencius's argument for human nature. Zafascynowana Chinami U. Blythe przekazała słuchaczom kilka swoich spostrzeżeń odnośnie mało znanej w szerszych kręgach społecznych myśli wielkich chińskich filozofów Konfucjusza i Mencjusza.

Po niej do przysłowiowej mównicy została poproszona Anouk Zuurmond z University of Groningen (Holandia), która przedstawiła referat pt. Ayn Rand and the educational values of objectivism. Wymieniona w tytule referatu twórczyni filozofii obiektywizmu zainteresowała A. Zuurmond jako autorka dwóch powieści - Źródło (1943) i Atlas zbuntowany (1957). Dla obu wspólnym motywem wydaje się być obiektywistyczna krytyka edukacji prowadzonej przez pedagogów, którzy „zapomnieli”, że kiedyś sami byli dziećmi. To zapomnienie powoduje, że przypisują sobie kompetencje i wiedzę, które nie tolerują żadnego sprzeciwu, a jedynie ślepą subordynację.

Do ostatniej, 10. sesji, przystąpiono po krótkiej przerwie. Na początku referat zaprezentował Piotr Warych z Wyższej Szkoły Pedagogiki i Administracji im. Mieszka I w Poznaniu. Tytuł wystąpienia brzmiał: The concept of love and friendship and its importance in contemporary education. W scholastyczny sposób 
prelegent omówił greckie terminy odnoszące się do miłości, wskazując, że warte są one zastosowania we współczesnej edukacji.

Po nim głos zabrał Rafał Godoń z Uniwersytetu Warszawskiego, który podjął temat Ethical aspects of schooling. Creativity in teaching and learning. Przedmiotem wystąpienia był projekt pt. „Akademia sztuki myślenia”, który był realizowany w latach 2017-2019, we współpracy z wybranymi szkołami średnimi Warszawy. Jego celem było rozwinięcie u młodzieży kompetencji krytycznego myślenia. Uzyskane wyniki zachęcały, zdaniem R. Godonia, do podejmowania wysiłków przybliżania młodzieży dziedziny wiedzy, jaką jest filozofia.

Na zakończenie odbyła się krótka ceremonia zamknięcia konferencji. Główny jej organizator, R. Godoń, podziękował gościom za przybycie, a w imieniu tych ostatnich N. Burbules wyraził wdzięczność za serdeczną i naukową atmosferę podczas dwudniowych obrad. Kolejne spotkanie za dwa lata będzie już pierwszym małym jubileuszem - 10-lecia warszawskiej konferencji pt. „Ethics and Education”. 


\section{Sprawozdanie $z$ uroczystości nadania profesorowi Bogusławowi Śliwerskiemu tytułu doktora honoris causa przez Uniwersytet Kardynała Stefana Wyszyńskiego w Warszawie, 25 czerwca 2020 roku}

Dnia 25 czerwca 2020 roku odbyła się w Uniwersytecie Kardynała Stefana Wyszyńskiego w Warszawie (UKSW) uroczystość nadania tytułu doktora honoris causa profesorowi Bogusławowi Śliwerskiemu. Z wnioskiem w tej sprawie do Senatu UKSW zwróciła się Rada Wydziału Nauk Pedagogicznych. Recenzentami dorobku profesora B. Śliwerskiego byli prof. dr hab. Agnieszka Cybal-Michalska i prof. dr hab. Józef Górniewicz. Uchwałę o nadaniu tytułu podjął Senat UKSW w dniu 27 lutego 2020 roku. W uzasadnieniu wskazano, że: „Profesor Bogusław Śliwerski należy do elitarnego grona współczesnych uczonych o międzynarodowej renomie. Jest wybitną osobowością, która poprzez swoją szeroką działalność oddziałuje na aktywność naukowo-badawczą, dydaktyczną i organizacyjną polskiego środowiska pedagogicznego oraz na tożsamość polskiej myśli pedagogicznej. Nieustannie wprowadza zaczyn do nowych badań i dyskusji poprzez oryginalne spojrzenie na pedagogikę, wszechstronność i interdyscyplinarność naukową. Posiada imponujący dorobek publikacyjny. Prowadzi działalność ekspercką i doradczą w różnych gremiach krajowych i zagranicznych. Senat UKSW zwraca również uwagę na wybitne osiągnięcia Laureata w budowaniu mostów solidarności między różnymi środowiskami naukowymi" (Uchwała nr 25/2020).

Do tej pory profesor B. Śliwerski otrzymał tytuł doktora honoris causa od trzech polskich uniwersytetów: Uniwersytetu Marii Curie Skłodowskiej w Lublinie (2014), Uniwersytetu Kazimierza Wielkiego w Bydgoszczy (2016) i Katolickiego

* Dr hab. Dariusz Stępkowski, prof. ucz., Uniwersytet Kardynała Stefana Wyszyńskiego w Warszawie, Wydział Nauk Pedagogicznych; e-mail: d.stepkowski@uksw.edu.pl. 
Uniwersytetu Lubelskiego Jana Pawła II w Lublinie (2017), i zagranicznej jednostki naukowej - Narodowej Akademii Nauk Pedagogicznych Ukrainy (2019). Ponadto jest on profesorem honorowym Uniwersytetu Warmińsko-Mazurskiego w Olsztynie i Uniwersytetu Śląskiego.

Uroczystość nadania tytułu i wręczenia dyplomu doktora honoris causa odbyła się w auli Jana Pawła II, w której zgromadzili się zaproszeni goście i przedstawiciele środowiska naukowego. Z uwagi na pandemię w uroczystości mogła wziąć udział ograniczona liczba osób. Jej przebieg był transmitowany na żywo w internecie.

Uroczyste zebranie rozpoczęło się od odśpiewania hymnu państwowego. Następnie głos zabrał rektor UKSW, ks. prof. dr. hab. Stanisław Dziekoński, który powitał laureata i zgromadzone osoby, a w szczególności Agnieszkę Śliwerską, małżonkę profesora B. Śliwerskiego; rektora Akademii Pedagogiki Specjalnej im. M. Grzegorzewskiej, prof. dr. hab. Stefana Kwiatkowskiego; rektora Chrześcijańskiej Akademii Teologicznej w Warszawie, prof. ucz., dr. hab. Bogusława Milerskiego; dziekana Wydziału Nauk o Wychowaniu Uniwersytetu Łódzkiego, prof. dr hab. Danutę Urbaniak-Zając; przewodniczącą Polskiego Towarzystwa Pedagogicznego, prof. dr hab. Joannę Madalińską-Michalak oraz oboje recenzentów - prof. dr hab. Agnieszkę Cybal-Michalską i prof. dr. hab. Józefa Górniewicza. Rektor UKSW podziękował profesorowi B. Śliwerskiemu za przyjęcie tytułu i podkreślił, że jest to wyraz wdzięczności nie tylko Wydziału Nauk Pedagogicznych UKSW, lecz także całego środowiska akademickiego uczelni za jego wkład w budowanie mostów porozumienia i wzajemnego szacunku.

Później prof. ucz., ks. dr. hab. Zbigniew Babicki, prodziekan Wydziału Nauk Pedagogicznych UKSW, odczytał wspomnianą powyżej uchwałę Senatu UKSW. Po czym prorektor UKSW ds. studenckich i kształcenia, prof. ucz., dr hab. Anna Fidelus, odczytała laudację, którą przygotował promotor - prof. dr hab. Jarosław T. Michalski, nieobecny na uroczystości. W laudacji naszkicowany został życiorys naukowy laureata i jego wkład w rozwój nauk o wychowaniu w Polsce. W dalszej części uroczystości głos zabrał prof. ucz., ks. dr hab. Z. Babicki, prodziekan Wydziału Nauk Pedagogicznych UKSW, który oczytał sporządzony w języku łacińskim tekst na dyplomie doktoratu honoris causa. Aktu uroczystego wygłoszenia formuły nadania tytułu i wręczenia dyplomu dokonał rektor UKSW, ks. prof. dr hab. S. Dziekoński. Zgodnie z ceremoniałem został odśpiewany hymn Gaude Mater Poloniae. Później prorektor UKSW ds. nauki i współpracy międzynarodowej i równocześnie rektor elekt, ks. prof. dr hab. Ryszard Czekalski, odczytał list gratulacyjny nadesłany przez Radę Doskonałości Naukowej i Centralnej Komisji ds. Stopni i Tytułów.

Po tym głos zabrał dostojny doktor honoris causa, który wygłosił wykład zatytułowany Prymas Tysiąclecia kardynał Stefan Wyszyński - pedagogia odwagi i pozytywnego oporu wobec przemocy. Na wstępie nawiązał do swoich osobistych związków z UKSW, uczelnią, która zaszczyciła go najwyższą godnością, jaką współcześnie uczony może otrzymać za swoją działalność. W nawiązaniu do postaci 
i nauczania kardynała Stefana Wyszyńskiego profesor B. Śliwerski zwrócił uwagę na wypowiedzi Prymasa pozostające do dziś wezwaniem do odwagi i pozytywnego oporu wobec przejawów dyskryminacji chrześcijaństwa w społeczeństwie polskim. W odniesieniu do szkoły, która wciąż pozostaje przedmiotem sporu ideologicznego, mówca przytoczył następujące słowa Prymasa Tysiąclecia: „Szkoła jest narodowa i należy do narodu, do rodziny i społeczeństwa, a nie do takiej czy innej partii, sekty czy ugrupowania zajmującego się niechwalebnym, a nawet wrogim i szkodliwym dla Narodu i państwa dziełem - wyrywania wiary z serc dzieci i młodzieży. [...] nie ma takiej władzy a ziemi, która mogłaby bez pogwałcenia wolności odmówić rodzicom prawa do wychowania dzieci w duchu religijnym".

$\mathrm{Na}$ zakończenie doktor honoris causa podziękował organom i władzom uniwersytetu, w tym jego rektorowi, dziekanowi Wydziału Nauk Pedagogicznych i całej społeczności akademickiej za obdarzenie go zaszczytnym tytułem. Słowa wdzięczności skierował również do swojej małżonki, a także mamy, która uczestniczyła w uroczystości on-line, rodzeństwa i współpracowników przybyłych z Uniwersytetu Łódzkiego. Kończąc, stwierdził, że swoją pracę traktuje jako służbę Bogu i Ojczyźnie, w tym nauce i oświacie.

Po wykładzie ponownie głos zabrał rektor UKSW, ks. prof. dr. hab. Stanisław Dziekoński, który podziękował za przypomnienie dziedzictwa Prymasa Tysiąclecia w tym szczególnym dla UKSW roku jubileuszu 2o-lecia istnienia i beatyfikacji kard. Stefana Wyszyńskiego. Uroczystość zamknęło odśpiewanie studenckiej pieśni Gaudeamus igitur. 